\title{
Exploring Youth Participatory Action Research in Urban Schools: Advancing Social Justice and Equity-Based Counseling Practices
}

\author{
Amy L. Cook \\ University of Massachusetts Boston \\ Ian Levy \\ Manhattan College \\ Anna Whitehouse \\ University of Massachusetts Boston
}

\begin{abstract}
Youth Participatory Action Research (YPAR) is emerging as a group counseling practice that focuses on topics that are of personal interest to youth and aims to promote social change. Although YPAR has been found to facilitate critical consciousness, assist with youth self-identity development, and promote social change, few researchers have examined its application in counseling. The present study explored six school counselor trainees' perceptions of YPAR as a therapeutic intervention and its impact on counseling skill development and how it relates to multicultural and social justice counseling competencies. The themes that resulted from the Interpretative Phenomenological Analysis for YPAR as a counseling practice were: (1) fun, interactive, youth-centered approach, not like counseling or therapy, (2) implementation of challenges requiring planning, time, and commitment, (3) collaborative supports to step out of comfort zone, overcome initial hesitancy, and welcome new learning experience, (4) development of counseling skills and confidence as a counselor, and (5) understanding differences and increasing self-awareness and advocacy skills. Discussion and implications for school counseling practice are provided.
\end{abstract}

Keywords: Youth Participatory Action Research; School Counseling; Positive Youth Development; Social Justice; Urban Schools

(C) 2020 Cook, Levy, \& Whitehouse. Free to copy and share for education and scholarship under a Creative Commons Attribution NonCommercial-NoDerivatives 4.0 License. 


\section{Introduction}

Researchers have urged the need for culturally competent counselors to enter the field with knowledge of multiculturalism to work with diverse clients (Hook et al., 2016; Richardson \& Molinaro, 1996; Sue et al., 1992; Vera \& Speight, 2003). This call for multicultural competence is reflected in the American Counseling Association (ACA) Code of Ethics (ACA, 2014) and the Multicultural and Social Justice Counseling Competencies (Ratts et al., 2016). While these policy recommendations deserve praise, studies have shown that Black and Brown clients experience fear, mistrust, and discrimination from counseling professionals (Ahmed et al., 2011; DayVines et al., 2007; Lindsey \& Marcell, 2012). Furthermore, Black and Brown clients are skeptical of seeking help from counselors (Earl et al., 2011, Lindsey et al., 2013). Existing counseling approaches to clinical models have been critiqued as acultural, often isolating clients of color (Tao et al., 2015). In response to these issues, scholars have argued for the use of action-oriented counseling practices to counter problematic power-dynamics (Smith \& Chambers, 2015) and allow people of color, including youth of color, to feel engaged in, and lead the group counseling process (Cook \& Krueger-Henney, 2017). The purpose of this present study is to evaluate and gather insights from counselor trainees who co-facilitated a series of culturally responsive participatory action research groups with youth as part of pre-service training coursework.

\section{Youth Participatory Action Research Defined}

Participatory Action Research (PAR) uses community engagement strategies to actively involve community members in the research process (Baum et al., 2006; Cammarota \& Fine, 2008; Langhout et al., 2014). Distinct characteristics of PAR include an emphasis on advocating for equitable sharing of power between researchers and research participants (Baum et al., 2006). Youth participatory action research (YPAR) is a PAR paradigm that empowers youth to engage as partners and co-researchers (Smith et al., 2010). Rather than remain as recipients of counseling services, YPAR encourages youth to guide the research and counseling process through dialogic processes in ways that empower them to address issues of personal interest and importance (Hipolito-Delgado \& Lee, 2007; Smith et al., 2014).

The YPAR paradigm shares common goals with other counseling practices of promoting youth empowerment (Hipolito-Delgado \& Lee, 2007). YPAR roles within the research collective are blurred so that youth lead the research process, thereby strengthening youth self-efficacy and participation for social change (Hipolito-Delgado \& Lee, 2007). Although YPAR has facilitated critical consciousness, assisted with self-identity development, and affected social change, few researchers have examined its application in counseling (Cook \& Krueger-Henney, 2017; Smith et al., 2014; Smith et al., 2010). This article seeks to explore how YPAR as a youth empowerment model, can be used in counseling, including as a model for Hip Hop Therapy.

Youth empowerment. The YPAR paradigm is closely associated with and incorporates key features of youth empowerment theory. Youth empowerment involves creating a developmental process that allows youth to participate in taking control over their lives and social environment, attain resources and fundamental rights, and achieve life goals (Maton, 2008). The focus on individual development is a crucial component of positive youth development (PYD) (Lerner et al., 2000). PYD is rooted in Bronfenbrenner's (1979) ecological theory of development and contends that external and internal factors simultaneously impact development. One's immediate environment and their surrounding community and cultural contexts work together to shape development. PYD programs emphasize developing five " $\mathrm{C}$ 's" in youth: Competence, Confidence, Connection, Character, and Compassion (Bowers et al., 2010; Lerner et al., 2000). In addition, Christens (2012) contended that a relational component adds to the understanding of youth empowerment. Elements include collaborative competence, bridging social division, and facilitating others' empowerment allow for a better understanding of the connection between individual and community empowerment. 
YPAR is a model of youth empowerment that shifts the traditional roles of research to position youth as leaders and active participants in the research process (Cammarota \& Fine, 2008). In collaboration with a counselor, youth actively identify research topics, choose a focus, develop research methods, collect data, and decide upon action plans to disseminate research findings (Smith et al., 2010). Through the YPAR process, Langhout et al. (2014) found that participants developed relational empowerment, including collaborative competence, bridging social divisions, facilitating others' empowerment, and mobilizing community networks. YPAR, therefore, relates to youth empowerment paradigms through building relational empowerment skills and addressing community issues with adult facilitation.

Researchers have argued that YPAR goes beyond traditional models of youth empowerment by adding critical elements to these interventions (Cammarota \& Fine, 2008; Ozer \& Wright, 2012). Although youth empowerment programs provide opportunities for youth to recognize how social constructs influence their environment, YPAR allows youth to study these issues and, most importantly, how to find solutions to them, particularly issues that affect their well-being (Cammarota \& Fine, 2008). YPAR engages youth in understanding the nature of social obstacles and deriving solutions to increase self-efficacy and agency in social change.

YPAR dissemination. YPAR also provides an outlet for community engagement through the dissemination of research findings and implications (Smith et al., 2010). Various methods of dissemination have been used with YPAR, including outlets to school administration (Kohfeldt et al., 2011; Smith et al., 2010), the community (Berg et al., 2009; Jennings et al., 2006; Wilson et al., 2008), and online platforms (Ozer, 2017). One common method involves the participants creating a presentation with or without technological aids to introduce the research project, describe its purpose, explain how data were collected, and share findings (Cammarota \& Fine, 2008; Smith et al., 2010). Another creative outlet for research dissemination uses photovoice, where participants use photography to document and express their perspectives of the research project (Royce et al., 2006; Wang \& Burris, 1997). Other forms of dissemination include planning a community event, communicating findings and implications online, displaying participant artwork depicting relevant finding, and performing music lyrics disseminated through online medias (Berg et al., 2009; Jennings et al., 2006; Levy et al., 2019; Ozer, 2017; Wilson et al., 2008).

\section{YPAR and Counseling}

Engaging in YPAR provides experiences that integrate a number of counseling practices to facilitate personal and community empowerment (Hipolito-Delgado \& Lee, 2007). Smith et al. (2010) explained how YPAR programs work in concert with school counseling projects due to their similarities with empowerment models for counseling practice. The group processes allow for participants to actively study relevant issues and respond to them (Cook \& Krueger-Henny, 2017; Singh et al., 2012). In Smith et al. (2010), student members of the YPAR group reported profound impacts from their work that involved creating a PowerPoint presentation for their school's administration. Through their research efforts, youth participants expressed a sense of inspiration to pursue higher education and professional careers. Such YPAR experiences may facilitate youth development and are thus aligned with counseling goals.

\section{YPAR and Hip-Hop Therapy}

The YPAR paradigm allows for the incorporation of a number of counseling practices in choosing the research topic, its research methods, and dissemination of the results. For example, Hip-Hop Therapy (HHT) may be used to guide methodological practices and disseminate research findings through lyrical products. An obstacle impeding best counseling practices with youth is associated with establishing rapport with the youth clients; however, HHT is a model of youth counseling practice that can be used to encourage youth participation. As Allen (2005) described, "HHT uses Hip-Hop music and culture to engage youth and address their issues in therapy by encouraging them to reflect on Hip-Hop lyrics as they relate to the youths' own life 
experiences" (p. 30). HHT integrates music therapy, behavioral therapy, and narrative therapy through lyric analysis, self-reflection, facilitating behavior change, and allowing clients to share their story (Allen, 2005). Furthermore, allowing youth to express themselves through Hip-Hop when they closely identify this culture as a part of their identity brings an invaluable tool for the counselor to build rapport with clients (Gonzalez \& Hayes, 2009). Both YPAR and HHT give youth a voice for expressing their perspectives of issues affecting their daily lives and thus engages participation with youth participants (Allen, 2005; Smith et al., 2010).

With these similarities in mind, Levy et al. (2019) suggested that pairing HHT with YPAR principles may help counselors to facilitate dialogue about systemic issues that students face through emotional lyric production and group collaboration. The process of lyrical creation, production, and dissemination provides counselors and students the opportunity to engage in discussion about and address salient community issues and thus lends itself well to the YPAR paradigm (Levy et al., 2019). Levy et al. concluded that the combining of practices from the fields of HHT, YPAR, and school counseling offer students the opportunity to engage in relevant action research through group collaboration.

\section{Purpose of Study}

The present study focused on the implementation and outcomes of student counseling groups using YPAR with HHT and other dissemination practices in order to explore two research questions. RQ 1: How do school counselor trainees perceive the use of YPAR as a therapeutic intervention? RQ 2: How do school counselor trainees perceive engaging in YPAR and its impact on developing counseling skills, including multicultural and social justice counseling competencies? Given YPAR's potential for prioritizing youth advocacy in educational settings, exploring its connections to counseling practice allows for group research that is anchored within and elevates young people's voices and perspectives. Facilitating socially underserved youth access to and participation in research can transform the purposes of research to be more in sync with young people's lives and their communities.

\section{Method}

\section{Participants}

Participants included six school counselor trainees (five female and one male) who completed the practicum seminar and field placement experience at one of two urban high schools. Age ranged from 21 to 30 years old $(M=25.8, S D=4.6, N=6)$. All participants reported race/ethnicity as White. Half of the participants reported having less than two years of experience in the education field, and half reported having between two to four years of experience. Reported family income ranged from $\$ 20,000$ to $\$ 40,000$. Three participants reported growing up in a suburb, and three reported growing up in a rural location. Participants had completed an average of nine counseling courses $(S D=3.8, N=6)$ prior to practicum; all had completed one course in cultural diversity.

\section{Research Team}

The research team included two counselor educators and one school psychology doctoral student, and all identified as White and cognizant of their privileged positions as researchers and researcher-in-training. Each held previous research and professional experiences related to urban youth, with one counselor educator having extensive experience with Hip-Hop therapy. Researchers acknowledged power differentials and unique perspectives. In keeping with IPA, the researchers reflexively explored participant narratives, while attending to their experiences as experts. To practice reflexivity whilst deploying IPA, the researchers acknowledged the importance of cultivating self-awareness, through self-reflection, necessary to engage with the study data in a capacity that circumvented bias. This meant recognizing our privileged positions as White researchers as we 
simultaneously sought to elevate the voices of our trainees' perspectives and experiences. This also meant that all members of the research team practiced bracketing, or the putting aside of their prior beliefs about the study phenomena (Carpenter, 2007) prior to engaging with the data. Specifically, the researchers used a reflexive diary, where research team members could record thoughts, feelings, and perceptions, to both analyze their positions and bring about potential bias (Chan et al., 2013).

\section{Procedure}

Practicum trainees engaged in one 30-minute semi-structured interview during the last week of fieldwork. Interview questions (see Table 1) focused on participants' perceptions of using YPAR as a counseling approach and thoughts related to multicultural and social justice counseling competencies. Participants included six school counselor trainees enrolled in one of two practicum seminar sections who engaged in YPAR facilitation as a portion of fieldwork. In total, 14 counselor trainees completed a 100-hour practicum at one of two urban high schools, each with similar student demographics (over 90\% students of color and $75 \%$ eligibility for free lunch), and eight practicum students facilitated YPAR group work at each school. At the start of the semester, counselor trainees who facilitated YPAR groups were invited to participate in the study, which included engaging in a semi-structured interview at the completion of the practicum. Participation was voluntary and approved by the university's Institutional Review Board. Of the eight students involved in YPAR, six agreed to participate in the study.

\section{Table 1. Semi-Structured Interview Protocol}

1. What were your thoughts about engaging with students at this school prior to starting?

2. How did your expectations differ (or were they the same?)?

3. Please describe what it was like to engage in YPAR with your students.

4. What went particularly well?

5. What were you surprised about?

6. What do you think you could have done to improve?

7. Do you think your students developed as a result of participating in YPAR? If so, in what ways? If not, why not?

8. What do you think your high school students found particularly helpful?

9. Do you think YPAR allows you to connect with your students? If so, in what ways? If not, why not?

10. Do you think YPAR is an area of focus that should be incorporated into school counseling practice? If so, why? If not, why not?

11. What particular counseling skills are helpful in facilitating YPAR? In what ways?

12. Did engaging youth in YPAR help you to develop multicultural counseling skills? If so, how? If not, what would have been helpful?

13. Did engaging youth in YPAR help you to develop social justice counseling competencies? If so, how? If not, what would have been helpful?

The practicum seminar course was conducted at the high school by one faculty member, where counselor trainees engaged in school counseling-related activities one day per week alongside the faculty member. The faculty-supervised classroom guidance and counseling activities, including 1:1 counseling and group counseling, and provided regular individual feedback and supervision that focused on multicultural counseling skill development. Trainees completed readings related to social justice, multicultural counseling 
skill development and YPAR. They also submitted weekly journal reflections that encouraged increased selfawareness of White privilege and biases, as well as knowledge of race, racism, and power structures present in schools and within the counseling relationship (Cook et al., 2019). During seminar meetings, the faculty engaged trainees in discussions that supported counseling skill development, YPAR training and implementation, and facilitating self-awareness and knowledge of systemic racism.

Implementation framework. Trainees encouraged youth participants to engage in dialogue where they shared personal insights and experiences as they engaged in research processes. Emphasis was placed on elevating youths' lived experiences and attending to critical issues that were relevant to them in ways that overtly draw attention to race, class, and gender-specific realities of youths' lives (Cook \& Krueger-Henney, 2017). Through this shared process of dialogue, youth researchers co-identified topics that were of personal interest and relevance to investigate as the focus of their action research (Fox \& Fine, 2015; Smith et al., 2010).

Two different areas of focus were selected among the YPAR co-researchers: at one school, youth selected the topic of increasing student involvement in course selections; at the other school, youth selected outside of school stressors. The chosen topic was then critically examined to uncover invisible power structures that may preclude positive educational outcomes, allowing youth, with the support of their counselor trainee, to take action toward achieving personal goals. Trainees followed the YPAR cycle of investigation, involving dialogue to decide on a topic of focus, collect and analyze data, develop an action plan, and disseminate findings, all the while processing youths' reactions and feelings (Cammarota \& Fine, 2008).

More specifically, at the school where the topic of increasing student involvement in course selections was selected, youth co-researchers surveyed their fellow high school students to learn more about the issue. Next, they conducted research to identify other course options and pathways within the school district in comparison to academic options at nearby suburban schools. While conducting the research, youth coresearchers engaged in knowledge sharing and contributed to one another's understandings of the issue as each of the group members experienced it (Foster-Fishman et al., 2010). In concluding their data collection and analyses, youth co-researchers decided to disseminate their findings through a creating a poster and writing a letter to the school principal.

At the school where the topic involved outside of school stressors, youth co-researchers explored a range of difficult emotional experiences that impacted their ability to reach personal and graduation goals. Youth co-researchers engaged in dialogue regarding a variety of emotional stressors and then began to research information related to overcoming the identified stressors. Similar to the other school site, students engaged in knowledge sharing and contributed to one another's understanding of the issue to support the construction of hip hop songs that communicated their experiences (Foster-Fishman et al., 2010). Examples of songs created by youth included frustrations with school discipline policies, truancy, as well as neighborhood and familial concerns. The youth agreed to disseminate the findings through recordings that they shared with friends and family.

\section{Data Analysis}

The research team chose Interpretative Phenomenological Analysis (IPA) as an implementation framework to guide the investigation given its focus on appreciating participants' experiences and how they make sense of social contexts (Smith et al., 2009). IPA employs a phenomenological approach, whereby analyses produce a thorough and subjective account of perceptions and experiences instead of producing an objective statement of experiences (Pietkiewicz \& Smith, 2014). When conducting IPA, capturing meaning is the central focus rather than identifying the frequency of themes. Additionally, IPA requires an in-depth analysis of each participant's experience to appreciate the unique context of individual narratives as a first step toward making general statements (Pietkiewicz \& Smith, 2014). Therefore, we read each transcript numerous times to appreciate the trainees' perspectives and engaged in a step-by-step process of understanding trainees' 
experiences. In accordance with IPA, we aimed to produce meaning from the data, rather than apply an extant theory to guide the analyses.

Through engaging in multiple readings of the transcribed material, we identified meaningful units of text (codes). We then grouped these codes based on commonalities into lower-order themes. A thorough account of lower-order themes was identified (through attending to description), and meaning was assigned to themes (interpretative analysis) to appreciate trainees' perceptions and experiences. We documented connections between emergent lower-order themes to inform the development of higher-order themes. Each higher-order theme reflected groupings of subthemes, which, in turn, reflected groupings of codes.

This step-by-step process of thematic analysis was completed in stages. The first stage of analysis included carefully reading the transcripts numerous times, writing comments and notes, and highlighting words, sentences, or phrases that seemed to be meaningful for trainees. A sample note included: "Counselor learns to give youth initiative to change injustices." In this detailed way, the team examined each transcript individually and documented notes accordingly. This idiographic approach to analysis began with specific examples (initial codes) and progressively worked toward producing emergent lower-order themes that were grouped into higher order themes to represent generalized understandings (Smith et al., 2009). In producing the initial codes, we focused on material in each transcript that illuminated trainees' perceptions and experiences of engaging in YPAR with youth. We then returned to the initial codes and transcripts with the goal of identifying the main higher-order themes from the emergent lower-order themes using structural coding (Saldaña, 2013).

Two members of the research team engaged in triangulation of the analyses to verify interpretation of data. Triangulation refers to the cross-validation of findings to work toward achieving comprehensive understanding of the data (Patton, 2015). In the present study, the researchers conducted consistency verification by independently reviewing and documenting notes aside transcript content. Team members then discussed the similar and diverse ways data were understood, following an iterative consensus process to ensure rigor and reach an agreement regarding the content (Kvale \& Brinkmann, 2009). Triangulation of data consisted of the two investigators independently reviewing the data and identifying emergent codes and themes. We then discussed the diverse and similar ways the data were understood with the goal of reaching $100 \%$ agreement. In addition, an external auditor and doctoral student with expertise in IPA reviewed transcripts and themes to ensure rigor and reach a final agreement. The external auditor also engaged in the analysis of the coding and themes, and then we subsequently discussed any differences and similarities in coding identification. This process of triangulation and consistency verification was important to ensure that final revision to our thematic analyses best represented trainees' experiences. After completing cross-validation, a table of lower and higherorder themes was created that captured trainees' perceptions of YPAR group work in counseling (see Table 2). 
Table 2. Higher \& Lower-Order Themes

Fun, interactive, youth-centered approach, not like counseling or therapy
Therapeutic group environment that fosters rapport and connection
Focuses on issues of importance to youth
YPAR as a culturally relevant group space

Implementation challenges requiring planning, time, and commitment Requires planning to overcome time constraints 4

Experiencing pushback and reluctance from school stakeholders 2

Environment of collaborative support to step out of comfort zone, overcome initial hesitancy, and welcome new learning experience

Coming out of comfort zone/initial hesitancy

\section{Development of counseling skills and confidence as a counselor}

Growth in active learning skills

Learning the process of running a group

Navigating the balance of boundaries and blurring of counselor/youth roles

2

\section{Counselor development in understanding differences and increasing self-awareness and advocacy} skills

Fosters understanding of differences and increased self-awareness

Appreciation of different perspectives $\quad 4$

Growth in advocacy skills with focus on youth initiative and leadership $\quad 2$

Note. $n$ refers to the number of participants for whom each higher and lower order theme was salient.

\section{Results}

Through data analysis, twelve themes emerged, which were grouped into five higher-order themes and corresponding subthemes. The first two higher-order themes that were identified related to how counselor trainees perceive the use of YPAR as a therapeutic intervention (RQ 1). The third, fourth, and fifth higher-order themes related to counselor trainee perceptions of engaging in YPAR and its impact on developing counseling skills, including multicultural and social justice counseling competencies (RQ 2). Table 2 depicts the number of participant quotes that support each subtheme.

\section{RQ 1: Counselor Trainee's Perceptions of YPAR as a Therapeutic Intervention}

Theme 1: Fun, interactive, youth-centered approach, not like counseling or therapy. The first higherorder theme indicated that the YPAR groups deployed a fun, interactive, youth-centered approach, not like counseling or therapy, and included three subthemes: a) therapeutic group environment that fosters rapport and connection, b) focuses on issues of importance to youth, and c) YPAR as a culturally relevant group space.

Therapeutic group environment that fosters rapport and connection. Counselor trainees' felt the YPAR group provided a therapeutic environment that fostered rapport and connection. For example, some counselor trainees felt hip hop lyric writing created a safe and supportive medium for students to disclose emotions. One trainee stated, "I feel good kind of just helps them open up and it's a safer setting where they feel safer, like they feel 'okay, this isn't a therapy session, we're just talking hip hop here. We're just talking about my lyrics.” An additional trainee's comment further highlighted this subtheme, "We came up with themes, but they were 
able to spearhead the group. We have them writing lyrics based on their emotions and their experiences, and being like what does this relate back to?" In this particular quote, the counselor trainee spoke of group work as a creative process that facilitated sharing and the expression of thoughts and feelings, in turn supporting rapport building and connection.

Focuses on issues of importance to youth. A second lower-order theme that emerged included appreciating the focus on issues of importance to youth. One counselor trainee stated, "direction was critical and we're not just in here making music for an hour and shooting conversation, we are actually exploring certain themes that aren't necessarily academic but relevant to everything else that is going on in their lives." Further, counselor trainees appreciated how paying attention to issues of importance to youth resulted in a shift in power dynamics: "I like that it was focused on having the kids come up with what they want to change. Putting the initiative on them, instead of assuming that we as counselors know what's best for kids."

YPAR as a culturally relevant group space. The fun and integrative nature of YPAR fostered a culturally relevant group process. To highlight this subtheme, one trainee stated,

We have one collaboration, that hasn't been recorded, but there's a portion of the group where we open it with a song, discuss it as a group and...then we kind of come back and talk amongst themselves, whereas we're around but we're letting them discuss amongst themselves and it's a very positive way of seeing how they work together.

This statement illuminates the counselor trainee's observation that students took the initiative and engaged a culturally salient medium (hip hop lyric writing) in the YPAR process, which then strengthened group cohesion. The counselors were also struck by how using hip hop as a YPAR tool supported youth in producing a tangible product stating,

They were able to actually put their songs down on paper so to speak and he [professor] could play back to them and then he sent it off and then he emailed them. I feel like that's tangible results of something they've completed throughout the past couple months... It was a whole other level of passion incited so much confidence and encouragement.

Theme 2: Implementation of challenges requiring planning, time, and commitment. The second higher-order theme signified that implementation challenges required planning, time, and commitment and included subthemes: Requires planning to overcome time constraints and experiencing pushback and reluctance from school stakeholders.

Requires planning to overcome time constraints. When beginning to facilitate groups, trainees reported that the decision-making and action-oriented process required planning to overcome time constraints. One trainee shared, "the deciding part went on a little too long and they spent two weeks picking a topic. So, that probably should have been condensed so they had more time to actually do something." Other implementation barriers consisted of inconsistent school attendance among youth. A trainee reflected on this issue: "I just think it's a really cool approach. The only thing was the kind of inconsistency, which had nothing to do with the group itself. Just the group itself is only certain weeks and certain students can't make certain days."

Experiencing pushback and reluctance from school stakeholders. Counselor trainees reported experiencing pushback and reluctance from school stakeholders. For some, it was a challenge to initially engage students in YPAR: "I think just trying to get them motivated was a little difficult, but for the most part it's been really fun. The students are having a good time, I hope, that's what they told me. So, it's been really great to see what they can learn to do." 


\section{RQ 2: Perceptions of Counseling Skill Development and Multicultural Competency}

Theme 3: Collaborative supports to step out of comfort zone, overcome initial hesitancy, and welcome new learning experience. The third theme supports the assertion that, for counselor trainees, the YPAR group provided an environment of collaborative support to step out of one's comfort zone, overcome initial hesitancy, and welcome new learning experiences. The subtheme describes how trainees were coming out of their comfort zone and overcoming initial hesitancy.

Coming out of comfort zone/initial hesitancy. Several trainees spoke about feelings of anticipation entering a new "tough" setting. For example, one participant shared,

I was excited, super excited, but also I had to do self-reflecting like, "I am a White, female counselor coming in to an urban based classroom." How are the students going to connect with me? Are they going to connect with me? Lots of that, so I kind of had those kind of nerves, but overall I was so excited.

Another trainee posited that YPAR opened her up to learning new systems and cultures:

It was a first experience of sorts...because I grew up in a suburban White neighborhood and I felt like I needed to learn a lot first, or at least gain an understanding of how the culture works, how the system works, how the individual comes from. So, I came from a place of just wanting to listen a bit first and ask questions, kind of tread gently.

Theme 4: Development of counseling skills and confidence as a counselor. Counselor trainees described a sense of increased confidence and counseling skill development, including three subthemes: growth in active listening skills, learning the process of running a group, and navigating the balance of boundaries and blurring of counselor/youth roles.

Growth in active listening skills. Trainees experienced growth in active listening skills, including how to challenge youth to share through emphasizing the therapeutic relationship:

My personal relationships with the students, being able to listen to them, work with them today, summarize what's going on, being able to find those hidden pieces, like in their lyrics and tap into those inner feelings, and then push them a little bit further to expand.

Another participant spoke of the importance of being open and allowing youth to take the lead: "When we were talking about developing allies and encouraging talking to the counselors, they were like, 'What about social media? What about doing a survey?' I was like I didn't even think about that, this is awesome."

Learning the process of running a group. Another lower-order theme concerned trainees' growth in learning the process of running a group. A particular quote that exemplifies this growth details a trainee's development of skills to foster groups with adolescents in schools:

I wanted to make these PowerPoints type thing and for me that's an organizational thing. But, you also need like open-mindedness of course, like I said you have no idea what your group is going to say, do, or not do. So, being prepared to go with the flow and be flexible. But, also help direct them as well.

The trainee learned to trust the group process and relinquish control in supporting the youth.

Navigating the balance of boundaries and blurring of counselor/youth roles. Trainees spoke about how to balance the boundaries of counselor and youth roles. Leading the YPAR groups appeared to assist with the use of self-disclosure. A trainee reflected on this development:

We would have a dialogue, and there is a certain amount of disclosure that I felt comfortable giving on my end as sort of a way of relating to the student, and then I think in doing so gaining...and strengthening their relationship and their comfort in facilitating gave momentum to their creative abilities. 
Theme 5: Understanding differences and increasing self-awareness and advocacy skills. Counselor trainees developed an understanding of differences as well as increased self-awareness and advocacy skills, including three lower-order themes: fosters an understanding of differences and increased self-awareness, appreciation of different perspectives, and growth in advocacy skills with a focus on youth initiative and leadership.

Fosters understanding of differences and increased self-awareness. Trainees described the ways that running YPAR groups fostered an understanding of differences and increased self-awareness. Trainees' use of self-reflection increased a sense of awareness.

So, for me just learning about these lives that I don't live and really hard-hitting things that really just open your eyes and make you see things in other ways. I would say definitely; it kind of helps you do a lot of self-reflection.

Another trainee suggested that the self-reflection during the group process allowed her to cultivate empathic understanding of students' experiences and stated,

You really have to understand where kids are coming from. The first piece we did was identity and understanding what students think of themselves...so, taking their thoughts and feelings and then having us self-reflect and then put ourselves in their shoes, helping us to understand their personal identity has helped me see myself in a counselor role.

Appreciation of different perspectives. Counselor trainees also perceived skill development concerning appreciating different views, life experiences, and values. In the following quote, this trainee described the ability to understand the whole student and their environment:

I think it helped develop multicultural skills because you're always going to recognize based on the student you are going to get different answers and different responses....and a lot of the time that does have to do with where they are from, if there is a language barrier, what they are dealing with outside of school.

Another trainee spoke about appreciating the variety of life experiences youth bring to the group:

You have to think of aspects of their lives, what experiences are they having, whether that's in the school, outside the school, in the home. So, I think they are all going to bring in different things, but based off their culture they're going to see the world differently and having different opinions on different topics within the school.

Growth in advocacy skills with focus on youth initiative and leadership. A third and final lower-order theme pertains to trainees' growth in advocacy skills. While reflecting on their growth as a counselor, one participant said, "I think exactly like giving the kids initiative and seeing what they feel has been an injustice in the school." This statement illuminates how trainees learned to foster youth initiative to change injustices during their facilitation of YPAR groups. An additional statement further supports this theme. One individual stated,

It's valuable to be a soundboard for them, so they can feel comfortable in the space and just validate all of their feelings that they are bringing. Especially when it's a topic that is rooted in the school like the ones my students are dealing with.

In this quote, the trainee suggested that they learned how to validate youths' feelings and frustrations rooted in challenging experiences in school. 


\section{Discussion}

This study explored how counselor trainees perceived the use of YPAR as a therapeutic intervention and vehicle for developing counseling skills, including multicultural and social justice counseling competencies. Counselor trainees conducted YPAR groups during practicum fieldwork with urban youth. Several themes emerged suggesting support for the use of YPAR in school counseling. Counselor trainees perceived YPAR to be helpful in facilitating therapeutic connections and rapport with youth. Given that YPAR explicitly promotes intentional power sharing, while acknowledging systemic inequities, it is anticipated that youth would feel comfortable talking openly and honestly (Ozer et al., 2013).

Counselor trainees also emphasized their appreciation of YPAR's focus on issues of key relevance to youth, which they perceived as substantially different from traditional counseling practices. These findings may suggest the importance of supporting youth in leading the counseling process and transcending traditional approaches to therapy. Of note, the process of facilitating YPAR groups enabled counselor trainees to grapple with issues of power dynamics on their paths toward deploying culturally responsive and social justice-oriented interventions. While graduate programs prioritize supporting counselors-in-training in the practicing of basic active listening skills (Weger et al., 2010), this study shows how YPAR strategies can transcend traditional models of counseling to offer experiential opportunities that hone necessary multicultural and social justice skills among trainees, such as defusing problematic counselor-client power dynamics. Researchers who have conducted YPAR groups in schools envision its application as an opportunity for the youth of color to reclaim their voices and decision making in spaces where they are often "expected to be controlled by the system rather than in control of the system" (Kohfeldt et al., 2011, p. 34). Overall, counselor trainees appreciated the ways that YPAR empowers youth to guide the knowledge and awareness of issues that are impacting them as they see it for themselves (Cook \& Krueger-Henney, 2017).

Evidence in the current study suggests that allowing counselor trainees to engage in YPAR group facilitation during practicum can lead to a variety of positive outcomes relative to counseling skill development. Scholars posit that it is the role of the counselor educator to promote the professional advocacy of counselorsin-training, which requires that graduate students learn to be comfortable stepping outside of their comfort zones (Havlik et al., 2019). Findings in this study support the use of YPAR to meet this professional development need. En route to developing multicultural competence, Ratts et al. (2016) argued counselors needed to understand cultural differences and engage in practices that foster deep self-awareness. Multicultural development is particularly important given the data that suggest clients of diverse backgrounds often find counseling professionals untreatable, or unable to understand them and their experiences (Ahmed et al., 2011; Day-Vines et al., 2007; Lindsey \& Marcell, 2012). Therefore, the results of this study are promising in that the counselor trainees reported a more profound sense of self-awareness and an increased understanding of cultural differences. In support of allowing clients to feel understood and validated, Studer (2015) highlighted the significance of counselor trainees developing practical communication skills during practicum and internship experiences. In the current study, participants indicated they had further developed their active listening skills through YPAR group facilitation. Overall, trainee reports of being able to step out of their comfort zone, understand differences and increase in self-awareness, and active listening skill development all reinforce graduate coursework and outcomes relative to the totality of their pre-service training experience.

\section{Limitations}

Findings are limited due to the small number of counselor trainees and lack of racial diversity of participants. Although the study provides qualitative insight with respect to the application of YPAR in counseling training, it is not possible to extend the findings beyond the participants' experiences. Relatedly, the present study does not include the perspectives of the youth who engaged in the YPAR groups. Interviewing the high school students individually or as part of a focus group could provide greater understanding of the 
application of YPAR in counseling. Furthermore, there were additional limitations with respect to the qualitative analyses. Member checking with trainees was not conducted due to the logistics of the trainees having exited the counseling training program at the time of analyses completion. To account for this limitation, the external auditor was a doctoral student whose positionality and experiences were somewhat more related to trainees' experiences compared to the faculty researchers. Qualitative methods did not include ethnographic procedures to ascertain the integrity of YPAR implementation to ensure the principles of YPAR were adhered to throughout. Lastly, the use of IPA and its focus on capturing meaning rather than identifying the frequency of themes or applying itself to the calculation of intercoder reliability scores may be limiting insofar as it allows for a rich understanding of participant perceptions but is less able to reduce experiences into quantifiable meaning units. Thus, additional research is needed to further explore the application of YPAR in counseling.

\section{Implications and Conclusion}

The implications for this study are vast. Whereas prior research in school-based YPAR interventions seldom focuses on practices for counselors, the current study provides school counselors with preliminary support needed to advocate for the use of YPAR-based group work. The present study also lends support to the application of YPAR as a youth-centered impactful counseling approach. School counselors looking to innovate their ASCA (2012) national model comprehensive school counseling programs might consider integrating YPAR as a meaningful and engaging way to bring youth on their advisory councils. There are additional implications for use of YPAR in pre-service work with counselors to support counseling skill development by allowing them to facilitate groups as part of either their practicum or internship experiences.

YPAR training and implementation in fieldwork is just a start toward building cultural and race-related reflection. In particular, it is important to keep in mind the wide body of research that has identified the tendency for White Americans to avoid confronting issues of racism and White privilege due to the frequent experience of distressing emotions (D’Andrea \& Daniels, 1999; Kordesh et al., 2013). It behooves counselor educators to address these emotional responses in ways that facilitate self-awareness and promote authentic advocacy and anti-racism work in schools. The results of this study are just a beginning step toward exploring the application of YPAR in counselor education. Additional research is needed to explore how YPAR in counseling can promote equity-based practices in schools.

\section{Corresponding Author}

The authors declare that they have no conflicts of interest. Correspondence concerning this article should be addressed to Amy Cook Ph.D., Department of Counseling and School Psychology, Wheatley Hall Room 160, 100 Morrissey Blvd., University of Massachusetts Boston, MA 02125. 


\section{References}

Ahmed, S., Wilson, K. B., Henrikson Jr, R. C., \& Jones, J. W. (2011). What does it mean to be a culturallycompetent counselor? Journal for Social Action in Counseling \& Psychology, 3(1), 17-28. https:// openjournals.bsu.edu/jsacp/article/view/329

Allen, N. M. T. (2005). Exploring hip-hop therapy with high-risk youth. Praxis, 5, 30-36. https://www.luc.edu/ media/lucedu/socialwork/pdfs/praxis/Volume\%205.pdf

American Counseling Association. (2014). American Counseling Association Code of Ethics. https://www. counseling.org/docs/default-source/default-document-library/2014-code-of-ethics-finaladdress. pdf?sfvrsn $=96 \mathrm{~b} 532 \mathrm{c} 2$

American School Counselor Association. (2012). The ASCA national model: A framework for school counseling programs (3rd ed.). Alexandria, VA: American School Counselor Association.

Baum, F., MacDougall, C., \& Smith, D. (2006). Participatory action research. Journal of Epidemiology and Community Health, 60, 854-857. https://doi.org/10.1136/jech.2004.028662

Berg, M., Coman, E., \& Schensul, J. J. (2009). Youth action research for prevention: A multi-level intervention designed to increase efficacy and empowerment among urban youth. American Journal of Community Psychology, 43, 345-359. https://doi.org/10.1007/s10464-009-9231-2

Bowers, E. P., Li, Y., Kiely, M. K., Brittian, A., Lerner, J. V., \& Lerner, R. M. (2010). The Five Cs model of positive youth development: A longitudinal analysis of confirmatory factor structure and measurement invariance. Journal of Youth and Adolescence, 39, 720-735. https://doi.org/10.1007/s10964-010-9530-9

Bronfenbrenner, U. (1979). The ecology of human development: Experiments by nature and design. Harvard University Press.

Cammarota, J. \& Fine, M. (2008). Youth participatory action research. In J. Cammarota \& M. Fine (Eds.), Revolutionizing education (pp. 1-12). Routledge.

Carpenter, D. R. (2007). Phenomenology as method. In H. J. Streubert \& D. R. Carpenter (Eds.), Qualitative research in nursing: Advancing the humanistic imperative (pp. 75- 99). Lippincott.

Christens, B. D. (2012). Toward Relational Empowerment. American Journal of Community Psychology, 50, 114-128. https://doi.org/10.1007/s10464-011-9483-5

Chan, Z. C., Fung, Y. L., \& Chien, W. T. (2013). Bracketing in phenomenology: Only undertaken in the data collection and analysis process? The qualitative report, 18(30), 1.

Cook, A. L., Brodsky, L., Gracia, R., \& Morizio, L. J. (2019). Exploring multicultural and social justice counseling training outcomes on school counselor and youth development. Counseling Outcome Research and Evaluation, 10, 78-93. https://doi.org/10.1080/21501378.2017.1422681

Cook, A. L., \& Krueger-Henney, P. (2017). Group work that examines systems of power with young people: Youth participatory action research. Journal for Specialists in Group Work, 2, 1-18. https://doi.org/10.10 $\underline{80 / 01933922.2017 .1282570}$

D’Andrea, M. D., \& Daniels, J. (1999). Exploring the psychology of White racism through naturalistic inquiry. Journal of Counseling and Development, 77, 93-101. https://doi.org/10.1002/j.1556-6676.1999.tb02426.x

Day-Vines, N. L., Wood, S. M., Grothaus, T., Craigen, L., Holman, A., Dotson-Blake, K., \& Douglass, M. J. (2007). Broaching the subjects of race, ethnicity, and culture during the counseling process. Journal of Counseling \& Development, 85, 401-409. https://doi.org/10.1002/j.1556-6678.2007.tb00608.x

Earl, T., Williams, D., \& Anglade, S. (2011). An update on the mental health of Black Americans: 
Puzzling dilemmas and needed research. Journal of Black Psychology, 37, 485-498. https://doi. org/10.1177/0095798410396077

Foster-Fishman, P. G., Law, K. M., Lichty, L. F., \& Aoun, C. (2010). Youth ReACT for social change: A method for youth participatory action research. American Journal of Community Psychology, 46, 67-83. https:// doi.org/10.1007/s10464-010-9316-y

Fox, M., \& Fine, M. (2015). Leadership in solidarity: Notions of leadership through critical participatory action research with young people and adults. New Directions for Student Leadership, 2015, 45-58. https://doi.org/10.1002/yd.20152

Gonzalez, T., \& Hayes, B. G. (2009). Rap music in school counseling based on don Elligan's rap therapy. Journal of Creativity in Mental Health, 4, 161-172. https://doi.org/10.1080/15401380902945293

Havlik, S. A., Malott, K., Yee, T., DeRosato, M., \& Crawford, E. (2019). School counselor training in professional advocacy: The role of the counselor educator. Journal of Counselor Leadership and Advocacy, 6, 71-85. https://doi.org/10.1080/2326716X.2018.1564710

Hipolito-Delgado, C. P., \& Lee, C. C. (2007). Empowerment theory for the professional school counselor : A manifesto for what really matters. Professional School Counseling, 10, 327-332. https://doi.org/10.5330/ prsc.10.4fm1547261m80x744

Hook, J. N., Farrell, J. E., Davis, D. E., DeBlaere, C., Van Tongeren, D. R., \& Utsey, S. O. (2016). Cultural humility and racial microaggressions in counseling. Journal of Counseling Psychology, 63, 269-277. https://doi.org/10.1037/cou0000114

Jennings, L. B., Parra-Medina, D. M., Hilfinger-Messias, D. K., \& McLoughlin, K. (2006). Toward a critical social theory of youth empowerment. Journal of Community Practice, 14, 31-55. https://doi. org/10.1300/J125v14n01 03

Kohfeldt, D., Chhun, L., Grace, S., \& Langhout, R. D. (2011). Youth empowerment in context: Exploring tensions in school-based yPAR. American Journal of Community Psychology, 47, 28-45. https://doi. org/10.1007/s10464-010-9376-Z

Kordesh, K., Spanierman, L. B., \& Neville, H. A. (2013). White students' racial affect: Gaining a deeper understanding of the antiracist type. Journal of Diversity in Higher Education, 6, 33-50. https://doi. org/10.1037/a0030102

Kvale, S., \& Brinkmann, S. (2009). Interviews: Learning the craft of qualitative research interviewing (2nd ed.). Sage.

Langhout, R. D., Collins, C., \& Ellison, E. R. (2014). Examining relational empowerment for elementary school students in a yPAR program. American Journal of Community Psychology, 53, 369-381. https:// doi.org/10.1007/s10464-013-9617-Z

Lerner, R. M., Fisher, C. B., \& Weinberg, R. A. (2000). Toward a science for and of the people: Promoting civil society through the application of developmental science. Child Development, 71, 11-20. https://doi. org/10.1111/1467-8624.00113

Levy, I., Cook, A. L., \& Emdin, C. (2019). Remixing the school counselor's toolkit: Hip hop spoken word therapy and YPAR. Professional School Counseling, 22, 1-11. https://doi. org/10.1177/2156759X18800285

Lindsey, M. A., Chambers, K., Pohle, C., Beall, P., \& Lucksted, A. (2013). Understanding the behavioral determinants of mental health service use by urban, under-resourced Black youth: Adolescent and 
caregiver perspectives. Journal of Child and Family Studies, 22, 107-121. https://doi.org/10.1007/ $\underline{\text { s10826-012-9668-Z }}$

Lindsey, M. A., \& Marcell, A. V. (2012). "We're going through a lot of struggles that people don't even know about": The need to understand African American males' help-seeking for mental health on multiple levels. American Journal of Men's Health, 6, 354-364. https://doi.org/10.1177/1557988312441520

Maton, K. I. (2008). Empowering community settings: Agents of individual development, community betterment, and positive social change. American Journal of Community Psychology, 41, 4-21. doi:10.1007/s10464-007-9148-6

Ozer, E. J. (2017). Youth-led participatory action research: Overview and potential for enhancing adolescent development. Child Development Perspectives, 11, 173-177. https://doi.org/10.1111/cdep.12228

Ozer, E. J., Newlan, S., Douglas, L., \& Hubbard, E. (2013). “Bounded” empowerment: Analyzing tensions in the practice of youth-led participatory research in urban public schools. American Journal of Community Psychology, 52, 13-26. https://doi.org/10.1007/s10464-013-9573-7

Ozer, E. J., \& Wright, D. (2012). Beyond school spirit: The effects of youth-led participatory action research in two urban high schools. Journal of Research on Adolescence, 22, 267-283. https://doi.org/10.1111/ j.1532-7795.2012.00780.x

Patton, M. Q. (2015). Qualitative research and evaluation methods. (4th ed.). Sage.

Pietkiewicz, I., \& Smith, J. A. (2014). A practical guide to using Interpretative Phenomenological Analysis in qualitative research psychology. Czasopismo Psychologiczne - Psychological Journal, 20, 7-14. https://doi.org/10.14691/CPPJ.20.1.7

Ratts, M. J., Singh, A. A., Nassar-McMillan, S., Butler, S. K., \& McCullough, J. R. (2016). Multicultural and social justice counseling competencies: Guidelines for the counseling profession. Journal of Multicultural Counseling and Development, 44, 28-48. https://doi.org/10.1002/jmcd.12035

Richardson, T. Q., \& Molinaro, K. L. (1996). White counselor self-awareness: A prerequisite for developing multicultural competence. Journal of Counseling and Development, 74, 238 https://doi. org/10.1002/j.1556-6676.1996.tb01859.x

Royce, S. W., Parra-Medina, D., \& Messias, D. H. (2006). Using photovoice to examine and initiate youth empowerment in community-based programs: A picture of process and lessons learned. Californian Journal of Health Promotion, 4, 80-91. https://doi.org/10.32398/cjhp.v4i3.1960

Saldaña, J. (2013). The coding manual for qualitative researchers (2nd ed.). Sage.

Singh, A. A., Merchant, N., Skudrzyk, B., \& Ingene, D. (2012). Association for Specialists in Group Work: Multicultural and social justice competence principles for group workers. The Journal for Specialists in Group Work, 37, 312-325. https://doi.org/10.1080/01933922.2012.721482

Smith, L., Beck, K., Bernstein, E., \& Dashtguard, P. (2014). Youth participatory action research and school counseling practice: A school-wide framework for student well-being. Journal of School Counseling, 12(21), 12-20. http://search.ebscohost.com/login.aspx?direct=true\&db=eric\&AN=EJ1034747\&site=eh ost-live

Smith, L., \& Chambers, D. A. (2015). Decolonizing psychological practice in the context of poverty. In R. D. Goodman \& P. C. Gorski (Eds.), Decolonizing multicultural counseling through social justice (73-84). Springer.

Smith, L., Davis, K., \& Bhowmik, M. (2010). Youth participatory action research croups as school 
counseling interventions. Professional School Counseling, 14, 174-182. https://doi.org/10.5330/ prsc.14.2m62r11337332gt54

Smith, J. A., Flowers, P., \& Larkin, M. (2009). Interpretative phenomenological analysis: Theory, method, and research. Sage.

Studer, J. R. (2015). A guide to practicum and internship for school counselors-in-training (2nd ed.). Routledge.

Sue, D. W., Arredondo, P., \& McDavis, R. J. (1992). Multicultural counseling competencies and standards: A call to the profession. Journal of Counseling \& Development, 70, 10. https://doi. org/10.1002/j.1556-6676.1992.tb01642.x

Tao, K. W., Owen, J., Pace, B. T., \& Imel, Z. E. (2015). A meta-analysis of multicultural competencies and psychotherapy process and outcome. Journal of Counseling Psychology, 62, 337-350. https://doi. org/10.1037/cou0000086

Vera, E. M., \& Speight, S. L. (2003). Multicultural competence, social justice, and counseling psychology: Expanding our roles. The Counseling Psychologist, 31, 253-272. https://doi. org/10.1177/0011000003031003001

Wang, C., \& Burris, M. A. (1997). Photovoice: Concept, methodology, and use for participatory needs assessment. Health Education and Behavior, 24, 369-387. https://doi.org/10.1177/109019819702400309

Weger Jr, H., Castle, G. R., \& Emmett, M. C. (2010). Active listening in peer interviews: The influence of message paraphrasing on perceptions of listening skill. The International Journal of Listening, 24, 34-49. https://doi.org/10.1080/10904010903466311

Wilson, N., Minkler, M., Dasho, S., Wallerstein, N., \& Martin, A. C. (2008). Getting to social action: The Youth Empowerment Strategies (YES!) Project. Health Promotion Practice, 9, 395-403. https://doi. org/10.1177/1524839906289072 